\title{
Fabrication and Characterization of Hydrocolloid Dressing with Silk Fibroin Nanoparticles for Wound Healing
}

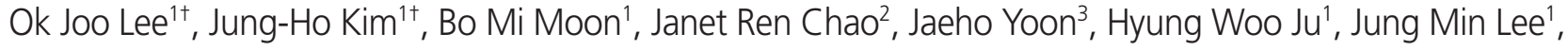 \\ Hyun Jung Park', Dong Wook Kim', Seung Ju Kim, Hae Sang Park ${ }^{5}$, Chan Hum Park1,5* \\ ${ }^{1}$ Nano-Bio Regenerative Medical Institute, Hallym University, Chuncheon, Korea \\ ${ }^{2}$ School of Medicine, George Washington University, Washington, D.C., USA \\ ${ }^{3}$ Laboratory of Cell and Developmental Signaling, National Cancer Institute-Frederick, Frederick, MD, USA \\ ${ }^{4}$ Department of Anesthesiology, Chuncheon Sacred Heart Hospital, School of Medicine, Hallym University, Chuncheon, Korea \\ ${ }^{5}$ Department of Otorhinolaryngology-Head and Neck Surgery, Chuncheon Sacred Heart Hospital, School of Medicine, Hallym University, Chuncheon, \\ Korea
}

Hydrocolloid dressings have been developed for many types of wound healing. In particular, dressing is a critical component in the successful recover of burn injuries, which causes a great number of people to not only suffer from physical but also psychological and economic anguish each year. Additionally, silk fibroin is the safest material for tissue engineering due to biocompatibility. In this study, we fabricated hydrocolloid dressings incorporating silk fibroin nanoparticles to enhance the efficacy of hydrocolloid dressing and then use this silk fibroin nanoparticle hydrocolloid dressing (SFNHD) in animal models to treat burn wounds. The structures and properties of SFNHD were characterized using tensile strength and Cell Counting Kit-8 assay. The results indicated the structural stability and the cellular biocompatibility of the hydrocolloid dressing suggesting that SFNHD can be applied to the treatment of wounds. To demonstrate the capacity of a silk fibroin hydrocolloid dressing to treat burn wounds, we compared SFNHD to gauze and Neoderm ${ }^{\circledR}$, a commercially available dressing. This study clearly demonstrated accelerated wound healing with greater wound structural integrity and minimal wound size after treatment with SFNHD. These observations indicate that SFNHD may be an improvement upon current standard dressings such as Gauze and Neoderm ${ }^{\circledR}$ for burn wounds.

Tissue Eng Regen Med 2016;13(3):218-226

Key Words: Hydrocolloid dressings; Silk fibroin nanoparticles; Biocompatibility

\section{INTRODUCTION}

Silk fibroin (SF) is a natural polymer composed of 18 amino acids and is particularly rich in glycine, alanine, tyrosine, and serine compared to the amino acids that compose collagen in skin [1-3]. Therefore, silk has the advantage of being more absorbent and waterproof compared to other polymers. Due to the biocompatibility of SF and its efficiency in wound healing, further research on SF is currently being studied $[4,5]$.

\footnotetext{
Received: July 15, 2015

Revised: September 29, 2015

Accepted: October 8, 2015

*Corresponding author: Chan-Hum Park, Nano-Bio Regenerative Medical Institute, Hallym University, 1 Hallymdaehak-gil, Chuncheon 24252, Korea. Department of Otorhinolaryngology-Head and Neck Surgery, Chuncheon Sacred Heart Hospital, School of Medicine, Hallym University, 77 Sakju-ro, Chuncheon 24253, Korea.

Tel: 82-33-240-5181, Fax: 82-33-241-2909, E-mail: hlpch@paran.com

'These authors contributed equally to this work.
}

The skin occupies the largest surface area in the human body and plays an important role in protecting the body from extreme temperatures through sweating and heat-insulation. The skin also serves as a physical barrier from outside pathogens. Some examples of skin damage include skin wounds, burns, and trauma. Wet dressings and ointments are used to treat and heal these skin damages.

Dressings must have a protective effect against the penetration of dirt and micro-organisms, be permeable to gas, and maintain a moist environment for skin wound healing. Additionally, wet dressings must have a non-adhesive characteristic in order to prevent secondary damage during the removal of the dressing [6]. Currently, the types of dressings being used include: a gauze, the transparent film, calcium alginate, polyurethane foam, hydrofiber, and hydrocolloid, hydrogel. In the past, gauze and bandages were commonly used. Recently, a variety of biomaterials have been utilized to produce a wet hydrocolloid 
dressing [7-10].

Hydrocolloids can be formed by dissolving natural polymers such as gelatin, collagen, carboxymethyl cellulose (CMC) with water. Additionally, hydrophilic synthetic polymers can also be dissolved in water to form hydrocolloids [11,12]. This dressing is suitable for burn wound treatment because the burn wound's exudate causes swelling to produce a hydrocolloid form $[13,14]$.

In this study, we prepared a biocompatible hydrocolloid dressing with SF nanoparticles and demonstrate its superior wound healing effects. Testing and analysis was performed in order to analyze the properties of adhesion, tensile strength, and integrity of shape. We also performed studies to determine the wound healing effects of silk fibroin nanoparticle hydrocolloid dressing (SFNHD) in animal models.

\section{MATERIALS AND METHODS}

\section{Materials}

To prepare the hydrocolloid dressing, we used sodium carboxymethyl cellulose (CMC), styrene-isoprene-styrene (SIS) and SF. SF particles were prepared using silk cocoons (Bombyx mori, $B$ mori). Characteristics of the hydrocolloid dressing were compared to those of Neoderm ${ }^{\circledR}$ (Everaid, Seoul, Korea), a commercial product.

\section{Silk fibroin solution}

Cocoons of $B$. mori silkworm silk were supplied by the Rural Development Administration, Suwon, Korea. The cocoons were boiled for $30 \mathrm{~min}$ in an aqueous solution of $0.02 \mathrm{M} \mathrm{Na}_{2} \mathrm{CO}_{3}$ and then washed with distilled water several times to remove the glue-like sericin proteins. Subsequently, the extracted silk was dissolved in a $\mathrm{CaCl}_{2}$ solution, and this solution was filtered through a miracloth (Calbiochem, San Diego, CA, USA) and dialyzed for 3 days to remove the salt. The final concentration of the aqueous SF solution was $8 \mathrm{wt} . \%$. The SF solutions were stored at $4^{\circ} \mathrm{C}$ before use to avoid premature precipitation.

\section{Silk fibroin nanoparticles}

A square mold was filled with $8 \mathrm{w} / \mathrm{t} \% \mathrm{SF}$ solution and incubated at $30^{\circ} \mathrm{C}$. All the water was evaporated to produce a SF membrane. After milling the SF membrane using a Ball milling method and a grinder, particles of various sizes were made (Fig. 1). A particle size analyzer SF NPs (Mastersizer 2000, Malvern, UK) was used to measure the distribution and size of the particles with a laser scattering method at $0.02-1000 \mu \mathrm{m}$.

\section{Fabrication of silk fibroin nanoparticle hydrocolloid dressing}

SIS was dissolved in bath at $190-200^{\circ} \mathrm{C}$ and mixed CMC and SF NPs $(1,5$, and $10 \%)$ for $30 \mathrm{~min}$. Polyurethane film was coat-

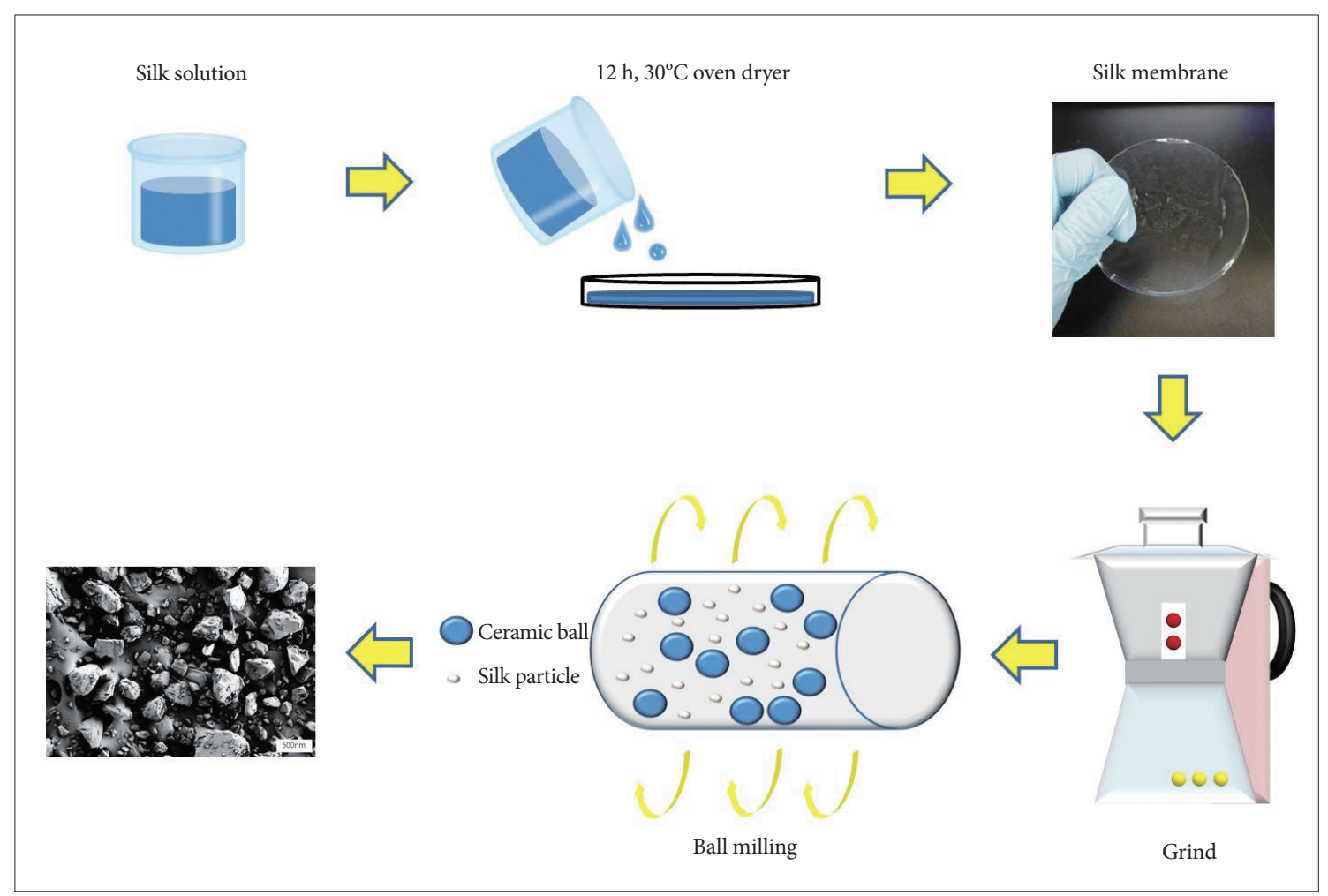

Figure 1. Schematic diagram of silk nanoparticles fabrication. 
ed the mixture solution using heat ruler. After cooling, a release paper was attached in the hardened hydrocolloid. The SFNHD was packed and sterilized using $\gamma$-ray ( $25 \mathrm{kGy})$.

\section{Swelling ratio}

The swelling properties were determined according to the previous method elsewhere. The SFNHDs were immersed in distilled water at room temperature for $24 \mathrm{~h}$. After the excess water was removed, the wet weight of the scaffolds $\left(\mathrm{W}_{\mathrm{s}}\right)$ was determined. The samples were then dried in an oven at $60^{\circ} \mathrm{C}$ under vacuum overnight, and the dry weight of scaffolds $\left(W_{d}\right)$ was determined. The swelling ratio and the water content in the SFNHDs were calculated as follows:

$$
\text { Swelling ratio }=\frac{\mathrm{W}_{\mathrm{s}}-\mathrm{W}_{\mathrm{d}}}{\mathrm{W}_{\mathrm{d}}}
$$

\section{Water uptake}

To determine the water absorption capacity of the produced SFNHD, the water uptake was measured. It is expressed as a percentage by dividing the absorbed weight $\left(\mathrm{W}_{\mathrm{s}}-\mathrm{W}_{\mathrm{d}}\right)$ of the SFNHD by the wet SFNHD weight $\left(\mathrm{W}_{\mathrm{s}}\right)$ of the absorbent SFNHD.

$$
\text { Water uptake }(\%)=\frac{\mathrm{W}_{\mathrm{s}}-\mathrm{W}_{\mathrm{d}}}{\mathrm{W}_{\mathrm{s}}} \times 100
$$

\section{Mechanical properties}

Universal testing machines (QM100S, Qmesys, Korea) measured the tensile strength of the SFNHD used. Measurement methods for each experimental group were measured three times at room temperature with a force of $8 \mathrm{kgf}$ by using a tensile strength tester.

\section{Adhesion testing}

Adhesion of the SFNHD was measured using Universal testing machines (QM100S). Samples were cut to a size of $1 \times 1 \mathrm{~cm}$ and attached to a stainless steel test plate. Adhesion was measured with a dry peel rate of $5 \mathrm{~mm} / \mathrm{s}$.

\section{Integrity value}

Samples with cut to a diameter of $8 \mathrm{~mm}$ and the initial weight (Wi) was measured. The sample was then immersed in a phosphate buffered saline solution and shaken for $24 \mathrm{~h}$. Samples were dried for $24 \mathrm{~h}$ in a $65^{\circ} \mathrm{C}$ oven. Dried weight (Wf) was then calculated to preserve the following equation.

$$
\text { Integrity value }(\%)=\frac{\mathrm{Wf}}{\mathrm{Wi}} \times 100
$$

\section{Cell viability}

The effect of salt pores on cellular function was determined based on a cell study with NIH 3T3 fibroblast cells, which were cultured on SFNHD in 96-well tissue culture plates. The fibroblast cells were cultured in Dulbecco's modified Eagle's medium supplemented with $10 \%$ fetal bovine serum, $100 \mu \mathrm{g} / \mathrm{mL}$ penicillin and $100 \mu \mathrm{g} / \mathrm{mL}$ streptomycin. The SFNHDs were sterilized by soaking the samples in 70\% ethanol for $30 \mathrm{~min}$. The wells were seeded at a density of 10000 cells/well onto samples. The media was changed two times per week. Cell proliferation of SFNHD was determined using a Cell Counting Kit-8 (CCK-8) assay $(\mathrm{n}=3)$ on days 1,3 , and 5 . Twenty microliters of the CCK8 solution was added to each well, and the cells were incubated for $2 \mathrm{~h}$. The absorbance was measured on a microplate reader (Molecular Devices, Sunnyvale, CA, USA) using $450 \mathrm{~nm}$ as the reference wavelength.

\section{Animal model}

Adult male Sprague-Dawley rats (8 weeks-old) were obtained from the animal center of Hallym University in Korea, housed for 1 week in a room with controlled temperature at $25 \pm 1^{\circ} \mathrm{C}$ and $\mathrm{RH} 60 \%$ and fed with a standard laboratory diet and water. The experimental care given to laboratory rats was in accordance with the regulations of the Animal Studies Committee at Hallym University.

\section{Measurement of burn wound healing}

To examine the effects of the SFNHD on the burn wound healing process, burn wounds were created on the back of a rat under anesthesia with a single intraperitoneal dose of $0.15 \mathrm{~mL}$ of Tiletamine/Zolazepam HCl (Zoletil, Virbac, France) and 0.1 $\mathrm{mL}$ Xylazine $\mathrm{HCl}$ (Rompun, Bayer Animal Health, Shawnee, KS, USA). After anesthetizing the rat, the fur on the back skin was removed. The back of the rat was exposed for $30 \mathrm{~s}$ to a de-



Figure 2. Particle size analysis of silk nanoparticles. 



Figure 3. The physical properties of hydrocolloid dressing. (A) Water uptake. (B) Swelling ratio. ${ }^{*} p<0.05$. N: Neoderm ${ }^{\circledR}, \mathrm{S} 1:$ silk fibroin nanoparticles $1 \%$, S5: silk fibroin nanoparticles $5 \%$, S10: silk fibroin nanoparticles $10 \%$.

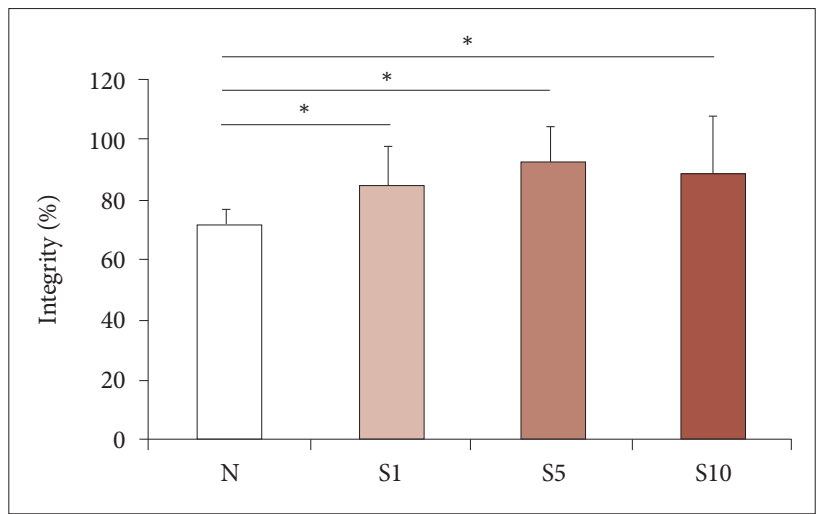

Figure 4. Tensile strength test of hydrocolloid dressing. ${ }^{*} p<0.05$. $\mathrm{N}$ : Neoderm ${ }^{\circledR}, \mathrm{S} 1$ : silk fibroin nanoparticles $1 \%$, S5: silk fibroin nanoparticles 5\%, S10: silk fibroin nanoparticles $10 \%$.

vice heated at $60^{\circ} \mathrm{C}$ to cause a deep second-degree burn $1.0 \times 1.5$ $\mathrm{cm}$ in size. The burn was confirmed by gross pathological changes. The SFNHD and Neoderm ${ }^{\circledR}$ were applied to the burn wound surface and subsequently covered with film dressing (3M Tegaderm $^{\mathrm{TM}}$ Film, $3 \mathrm{M}^{\mathrm{TM}}$ Health Care, MN, St. Paul, USA). Medical gauze, as a control group, was applied following the same procedure. The wound dressings (SFNHD, Neoderm ${ }^{\circledR}$, and medical gauze) were exchanged every 2 days for the first week and then once a week for the next 3 weeks. During this period, the burned wound site was photographed every other day and measured using INNERVIEW 2.0 software (INNERVIEW, Seongnam, Korea). The rats were sacrificed at 1, 3, 7, 14, and 21 days with a lethal dose of thiopental urethane and the wound skin was collected for analysis.

\section{Histological examination}

The collected skin tissue specimens were fixed in $4 \%$ buffered paraformaldehyde for at least $24 \mathrm{~h}$, progressively dehydrated in solutions containing an increasing percentage of ethanol $[70,80$, 90 and $100 \%(\mathrm{v} / \mathrm{v})]$, cleared in xylene, embedded in paraffin,

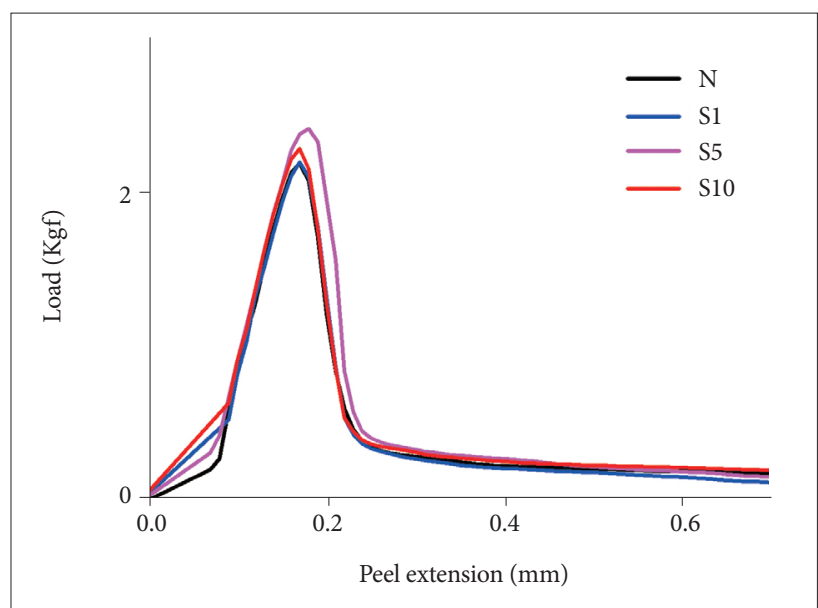

Figure $5.180^{\circ}$ peel strength test of hydrocolloid dressing. $\mathrm{N}$ : Neoderm $^{\circledR}$, S1: silk fibroin nanoparticles $1 \%$, S5: silk fibroin nanoparticles $5 \%$, S10: silk fibroin nanoparticles $10 \%$.

sectioned at a $5 \mu \mathrm{m}$ thickness, de-paraffinized and stained with hematoxylin and eosin or Masson's trichrome. After embedding the skin tissue in paraffin, tissue slices were de-paraffinized to probe for expression of proliferating cell nuclear antigen (PCNA). The PCNA-positive cells in the burn wound area were visualized with an immunoperoxidase technique using an antimouse PCNA antibody (Bioworld Technology, Louis Park, MN, USA). Histological observation was performed under a light microscope (Eclipse 80i, Nikon, Tokyo, Japan).

\section{Statistical analysis}

All experiments were expressed as means \pm standard deviation and performed with a minimum of $\mathrm{n}=3$ for each data point. A $\mathrm{t}$ test was used to compare groups with the GraphPad Prizm program (GraphPad Software, San Diego, CA, USA). 


\section{RESULTS}

\section{Particle size analysis}

To measure the size of the SF NPs crystals, a particle size analyzer was used (Fig. 2). SF NPs were determined to range between $500-700 \mathrm{~nm}$ in size.

\section{Physical properties}

A hydrocolloid dressing was prepared with 1\% (S1), 5\% (S5), and $10 \%$ (S10) SF NPs (Fig. 3). Water uptake and swelling ratios of the hydrocolloid dressings were measured. A control group was also tested using Neoderm ${ }^{\circledR}$. Water uptake of $S 1$ (44.58 \pm 8.48$)$ and S5 (43.44 \pm 9.62$)$ were lower than the water uptake of Neo$\operatorname{derm}^{\circledR}$ (56.54 \pm 6.27$)$. However S10 (57.14 \pm 12.36$)$ showed a slightly increased water uptake compared to the results of Neo$\operatorname{derm}^{\circledR}$. Swelling ratios were also measured for Neoderm ${ }^{\circledR}$ (1.33 \pm 0.33$), S 1(0.86 \pm 0.25), S 5(0.83 \pm 0.28)$, and S10 (1.5 \pm 0.36$)$.
The swelling ratio results confirmed that S10 demonstrated increased water absorption and swelling ratios in comparison with Neoderm $^{\circledR}$. Due to its hydrophilic natural polymers, SF NPs resulted in increased water uptake and Swelling ratio.

\section{Tensile strength}

In order to analyze elasticity, tensile strength of the hydrocolloid dressing was measured (Fig. 4). S10 (2.78 \pm 0.14$)$ demonstrated the greatest tensile strength in comparison to Neoderm ${ }^{\circledR}$ (2.38 \pm 0.11$), S 1(2.58 \pm 0.23)$, and S5 (2.65 \pm 0.33$)$. The tensile strength increased with increasing amounts of SF NPs. This result is thought to result from the viscosity of the SF NPs.

\section{Adhesive strength}

The adhesive strength of S1, S5, and S10 were compared to the adhesive strength of Neoderm ${ }^{\circledR}$ (Fig. 5). Our results demonstrated that adhesive strength in all groups appeared similar.
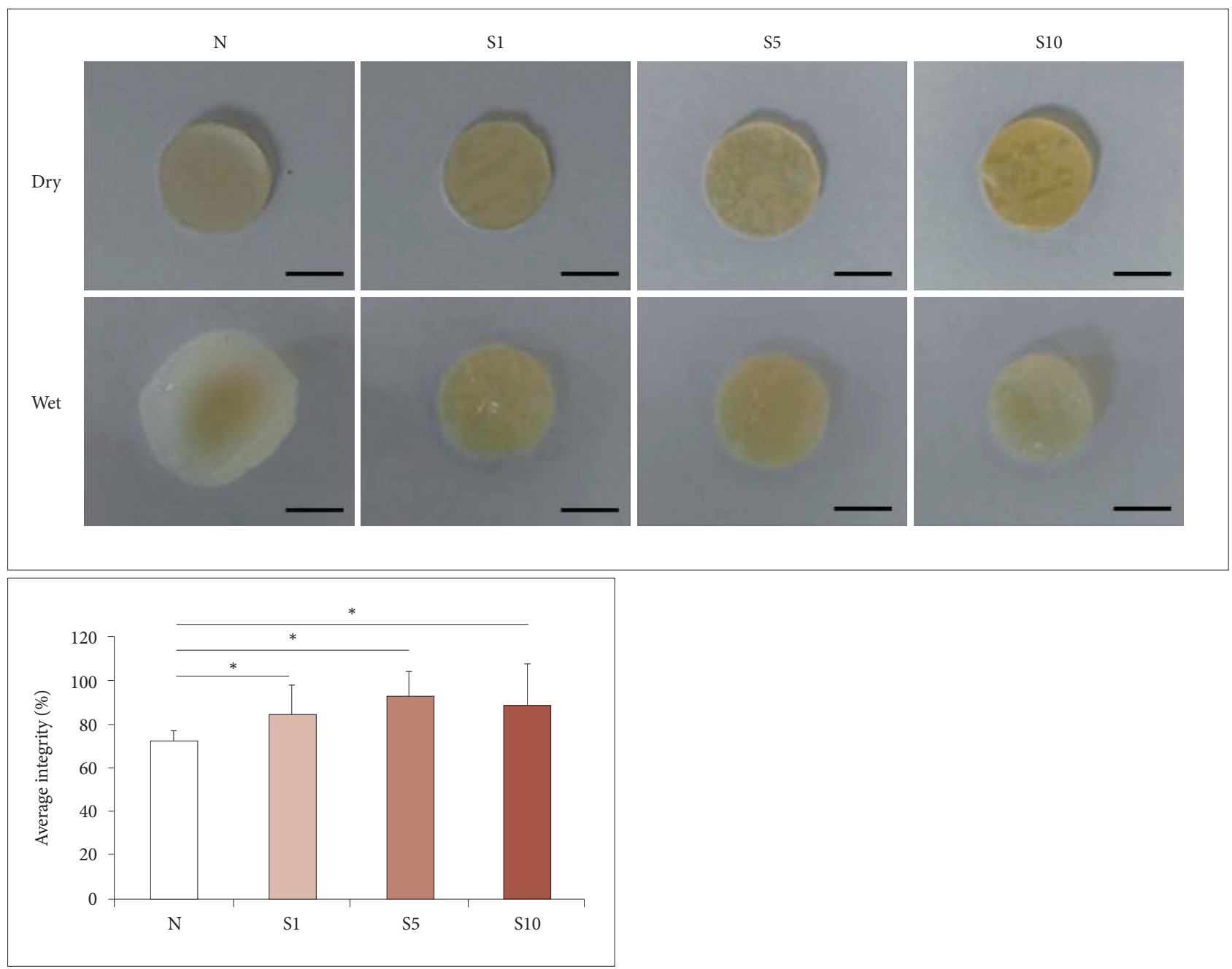

Figure 6. Integrity test of hydrocolloid dressing. ${ }^{*} p<0.05$. Scale bars: $4 \mathrm{~mm}$. N: Neoderm ${ }^{\circledR}$, S1: silk fibroin nanoparticles $1 \%$, S5: silk fibroin nanoparticles 5\%, S10: silk fibroin nanoparticles $10 \%$. 
Therefore, the SF content of nanoparticles does not affect adhesion.

\section{Shape integrity}

The shape integrity of the SFNHD was measured (Fig. 6). When Neoderm ${ }^{\circledR}$ was placed in water, it lost its shape. However, S1, S5, and S10 maintained their state in water. The shape integrity of Neoderm ${ }^{\circledR}, S 1, S 5, S 10$ was measured at values of $72 \%$, $85 \%, 93 \%$, and $88 \%$ respectively. These results suggest that in comparison to Neoderm ${ }^{\circledR}$, SFNHD will be more easily removed without remnants from the dressing.

\section{Cell viability}

To determine cell viability of a SFNHD, cell proliferation was measured at days 1, 3 , and 5 using CCK-8 (Fig. 7). On day 1 , the cell proliferation rate was similar in all experimental groups. However, by day 5 , the results showed that S1, S5, and S10 prompted greater cell proliferation than Neoderm ${ }^{\circledR}$. Cell proliferation was greatest in S10 and lower with smaller amounts of SF NPs implying that SF NPs are cellular biocompatible.

\section{Wound healing in burn tissue}

To investigate the effect of SF in burn injuries, we examined the wound healing effects in a rat burn model. We also measured the wound size after SFNHD treatment at different time points $(3,7,14$, and 21 days). As shown in Figure 8A, the wound area was slightly increased at 3 days by Neoderm ${ }^{\circledR}$, and S10 treatment. However, wound healing rapidly progressed with S10 treatment compared with the Neoderm ${ }^{\circledR}$ treatment between 7 and 21 days. At 14 days, the S10 had a residual wound area of $0.87 \pm 0.16$, while Gauze and Neoderm ${ }^{\circledR}$, had areas of $1.03 \pm 0.25$ and $1.02 \pm 0.13$ respectively. At 21 days, the $S 10$ had a residual

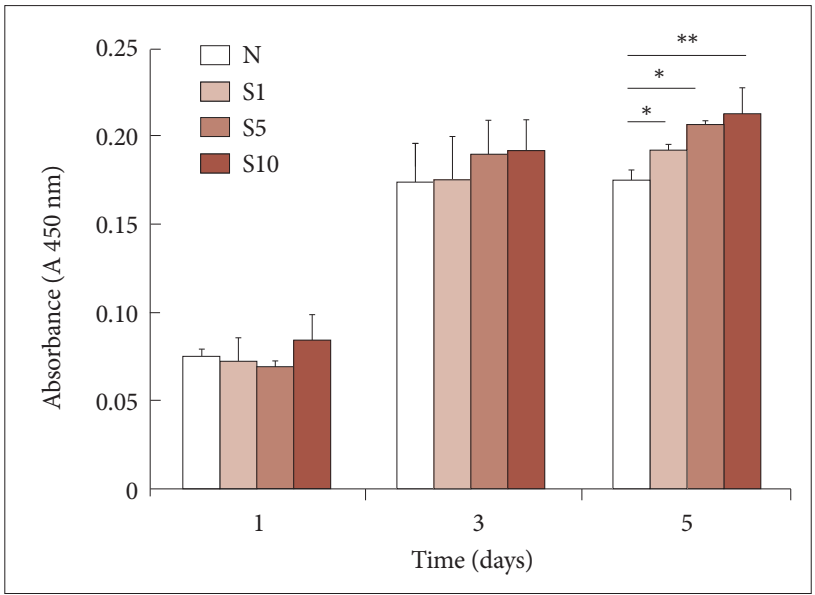

Figure 7. Cell viability measured by the Cell Counting Kit-8 assay. ${ }^{*} p<0.05,{ }^{* *} p<0.01$. N: Neoderm ${ }^{\circledR}, \mathrm{S} 1$ : silk fibroin nanoparticles $1 \%$, S5: silk fibroin nanoparticles $5 \%$, S10: silk fibroin nanoparticles $10 \%$. wound area of $0.32 \pm 0.07$, while Gauze and Neoderm ${ }^{\circledR}$ had areas of $0.60 \pm 0.22$ and $0.57 \pm 0.35$ respectively. S10 treatment resulted in the smallest residual wound area compared to Gauze and Neoderm $^{\circledR}$ at 14 days and 21 days (Fig. 8).

\section{Histological evaluation}

As shown in Figure 9A, blistering and edema (without any damage to the underlying fascia and muscle tissue) were induced by a second-degree burn. Interestingly, S10 treatment showed rapid re-epithelialization and a faster tissue regeneration compared with gauze and Neoderm ${ }^{\circledR}$ treatment during the entire wound healing period. Unlike the control- and Neoderm ${ }^{\circledR}$ treated groups, the S10-treated group showed a similar morphology to that of normal skin tissue at 14 days, even though fibroin clots still remained on the surface, and also exhibited a wound area that was almost regenerated without edema at 21 days. Our collagen assay results demonstrated that S10 treatment reduced destruction of collagen and accelerated the burn wound healing (Fig. 9B).

\section{PCNA expression}

As shown in Figure 10, S10 treatment increased PCNA expression compared with gauze and Neoderm ${ }^{\circledR}$ treatments at 7 days. We observed that dermis was regenerated in the S10-treated burn wound (black arrows). However, dermis regeneration was not observed in the gauze- or Neoderm ${ }^{\circledR}$-treated wound tissues.

\section{DISCUSSION}

In general, ideal wound dressing materials would have the following properties: 1) promotes a moist wound environment; 2) promotes wound healing; 3 ) does not adhere to the wound; 4) can be removed without pain or trauma; 5) be capable of absorbing excess exudate; 6) allows for gaseous exchange; 7) be non-cytotoxic to the healthy tissue; and 8) be antimicrobial/antifungal. Furthermore, the ideal wound dressing should be easy to use and cost-effective. Biomaterial dressings covered skin wounds in order to stabilize wound areas and can temporarily prevent the wounds from infection [15-17]. However, as biomaterials are further studied and technologies advance, in addition to simply stabilizing the wound and protecting it from infection, the role of wound dressings have expanded to actually treat the wound more effectively and to reduce the suffering of the wounded patients [18-20]. Various synthetic and natural polymers have been studied for use as biological materials for wound dressings including poly(glycolic acid), poly(L-lactic acid), and poly[(lactic acid)-co-(glycolic acid)], collagen, and silk. In particular, a number of studies have reported that $\mathrm{SF}$ is a good candidate for wound 
healing applications [10,21-23]. One study demonstrated that SF nanofibers had a notable effect on cell attachment and spreading of normal human keratinocytes and fibroblasts in vitro [10]. Another study showed that SF exhibited attachment and growth of fibroblast cells as well as collagen did [21]. Additionally, SF was shown to have beneficial immune system effects for wound healing such as SF-induced activation of mononuclear cells as measured by a lower interleukin- $1 \beta$ production when compared to reference materials such as poly(styrene) and poly(2-hydroxyethyl methacrylate) and also less inflammation and neutrophil/lymphocyte infiltration of the wounds when compared to Duo Active, a clinically-used dressing according to some studies [22,23].

In this study, we added hydrophilic polymer SF NPs to hydrocolloid dressing and hypothesized that this would improve the effectiveness of the dressing (Fig. 1). In order to test the effectiveness of our SFNHD, we compared the physical properties, tensile strength, adhesive strength, integrity of shape, and cell viability of S1, S5, and S10 to the characteristic of commercially available Neoderm ${ }^{\circledR}$ (Figs. 3-7). The results of tensile strength, peel strength, and integrity testing of SFNHDs were similar to those of Neoderm ${ }^{\circledR}$. However, physical property testing results such as those of water uptake and swelling ratio of SFNHDs were greater than those of Neoderm ${ }^{\circledR}$. Due to the hydrophilic
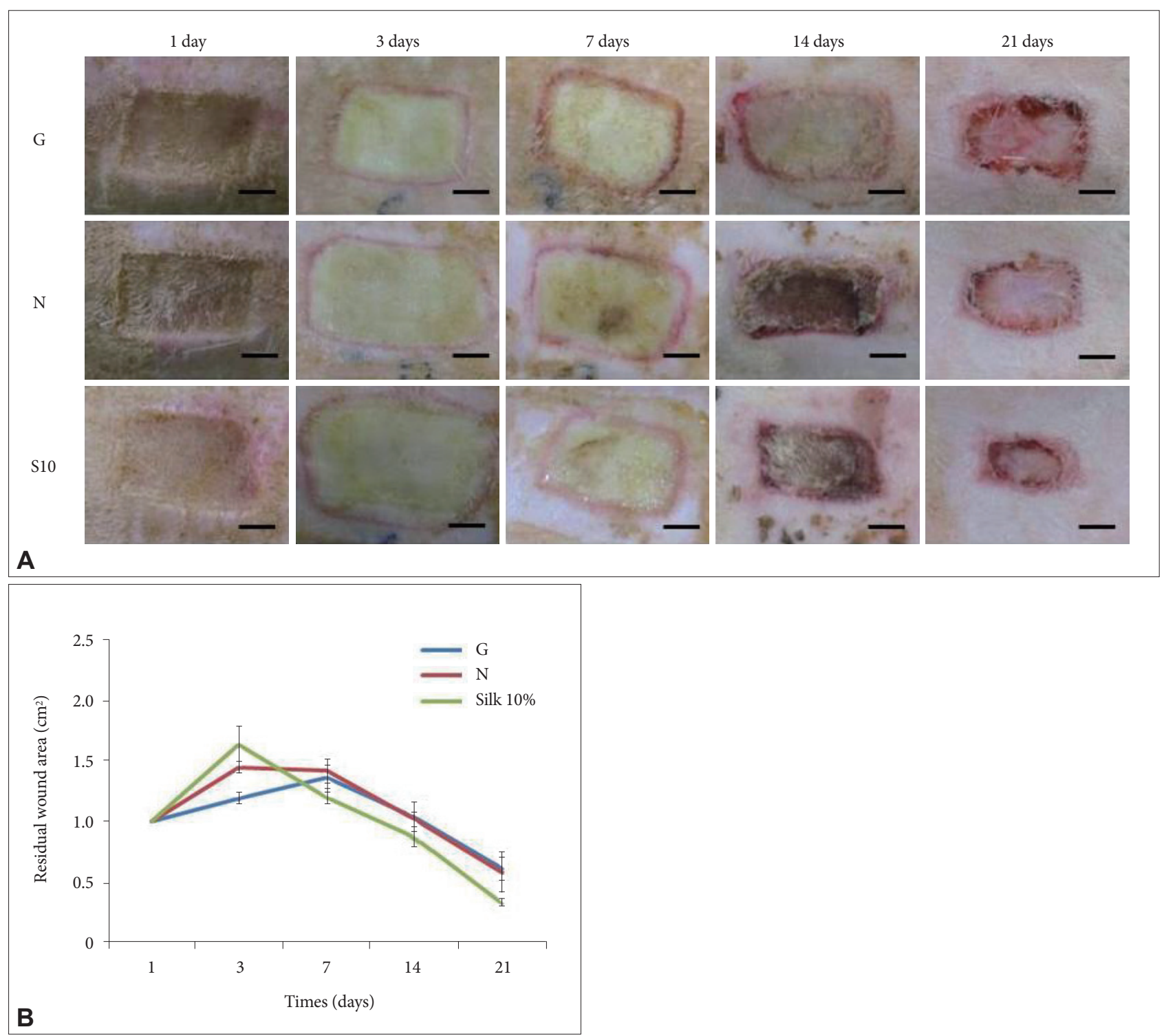

Figure 8. Effect of silk fibroin nanoparticle hydrocolloid dressing on dermal wound healing. (A) Gross observation of the wound area treated with different wound dressing materials. (B) Residual wound area change with the healing time and the silk fibroin hydrocolloid dressing. The results are represented as the mean \pm standard deviation $(n=5)$. Scale bars: 25 mm. G: gauze, N: Neoderm ${ }^{\circledR}$, Silk $10 \%$ : silk fibroin nanoparticles $10 \%$. 
properties of SF polymers, increased amounts of SF resulted in improved physical properties. In particular, water uptake and swelling ratio were greatest with S10. Furthermore, cell viability was found to be greatest in S10. Due to these results, S10 was chosen for further wound healing studies in animal models.

Burn injury induces several histological phenomena, such as necrosis of fibroblasts, atrophy of the hair follicles and increase in the density of collagen fibers. To analyze the wound healing progression with S10 treatment, we observed histological changes in burn tissues (Fig. 8). The $\mathrm{S} 10$ treated group showed a similar morphology to that of healthy tissue at 14 days and was almost regenerated without edema at 21 days. The histological changes induced by the S10 treatment included an increased density of collagen fibers, which have critical roles in regulating the structural integrity of tissue during wound healing (Fig. 9). These results therefore suggest that S10 treatment can improve the structural integrity of wound tissue.

Figure 10 shows cell nuclear antigen (PCNA) expression through immunohistochemical staining in S10 treated burn wound tissue during skin regeneration. At 7 days, S10 was the only treatment that resulted in a regenerated a dermis layer, suggesting that $\mathrm{S} 10$ accelerates burn wound healing in comparison to gauze and Neoderm ${ }^{\circledR}$.

In conclusion, SF NPs nps were used to produce a hydrocol-

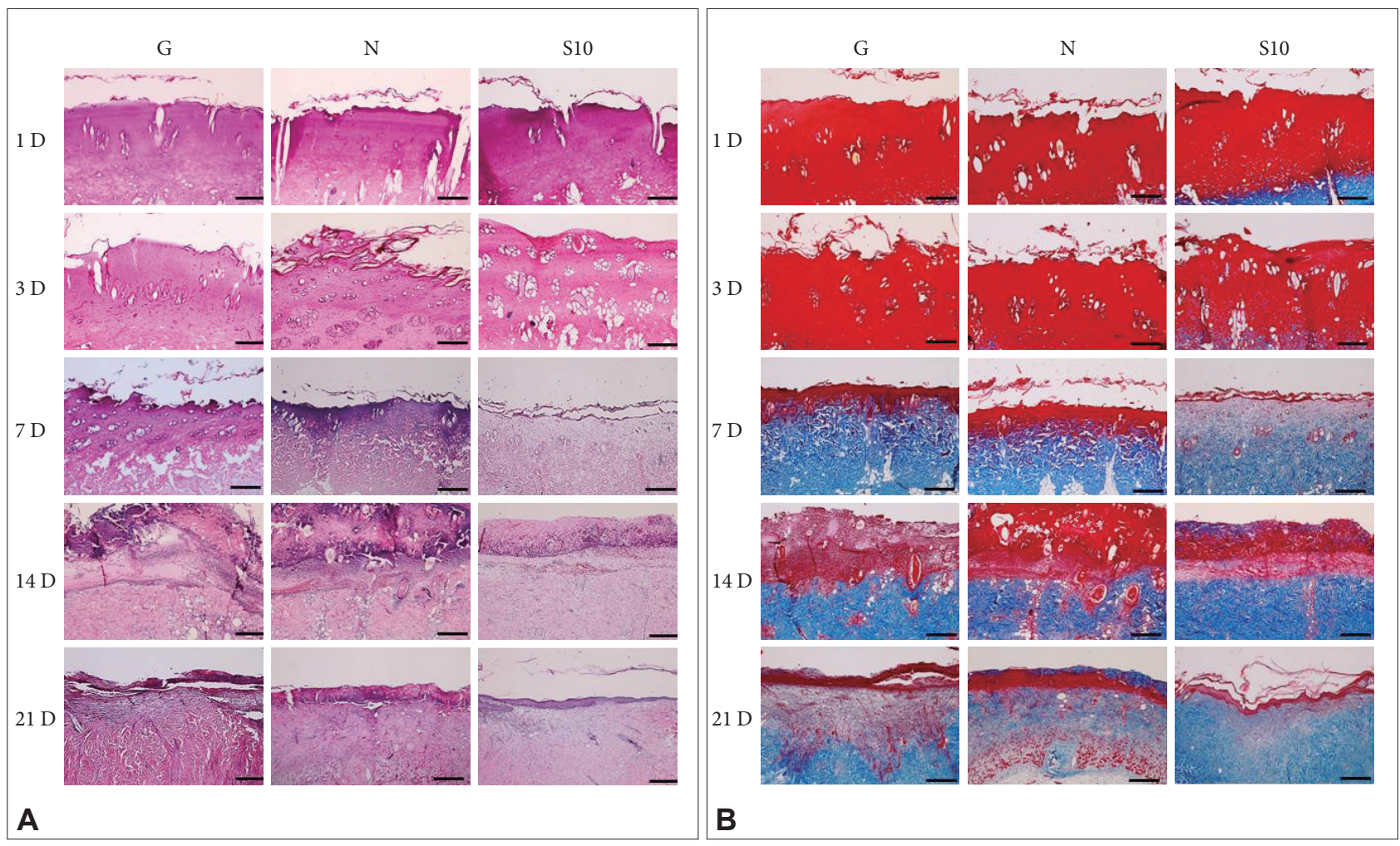

Figure 9. Histological evaluation of epidermal/dermal remodeling in burn wounds. (A) Hematoxylin and eosin stained images of burn wound tissue. (B) Masson trichrome stained images of burn wound tissue. Scale bars: $200 \mu \mathrm{m}$. G: gauze, N: Neoderm ${ }^{\circledR}$, S10: silk fibroin nanoparticles $10 \%$, D: day.

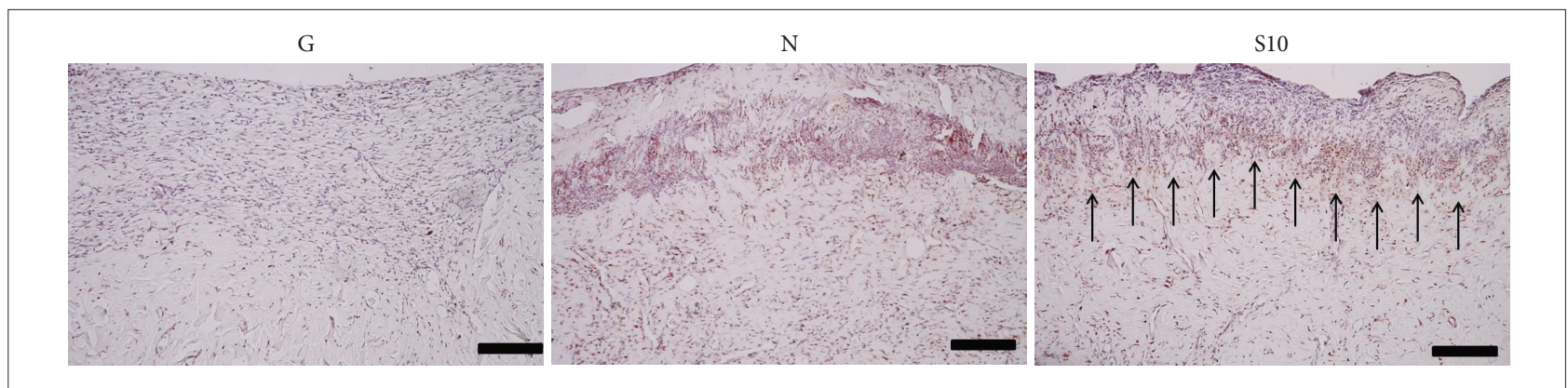

Figure 10. Immunohistochemical staining for proliferating cell nuclear antigen during skin regeneration. Image taken after 7 days. Scale bars: $400 \mu \mathrm{m}$. G: gauze, N: Neoderm ${ }^{\circledR}$, S10: silk fibroin nanoparticles $10 \%$. 
loid dressing and was experimentally compared to Neoderm ${ }^{\circledR}$. Our results indicated that SFNHDs showed similar or increased water uptake and swelling ratios compared to Neoderm ${ }^{\circledR}$. It was also demonstrated that increasing the content of SF NPs in dressing helped maintain the shape of the dressing after adding water. The tensile strength also increased with increasing amounts of SF NPs indicating that SF NPs increased the elasticity of the SFNHD, likely due to their viscosity. Further, results showed that cell growth rate increased with the content of the SF NPs through CCK-8 assay.

In this study, a hydrocolloid dressing containing SF NPs were found to be suitable and biocompatible revealing that SFNHD could be used as a wound dressing. In animal models, SFNHD reduced burn wound size and increased the density of collagen fibers when compared to commercially available dressing, Neoderm $^{\circledR}$. In addition to greater structural integrity of wounds, SFNHD resulted in increased PCNA expression when compared to Neoderm ${ }^{\circledR}$, suggesting accelerated burn wound healing.

\section{Acknowledgements}

This work was supported by Hallym university research fund and the National Research Foundation of Korea (NRF) grant funded by the Korea government (MSIP) (NRF2015R1A4A1041631), Republic of Korea.

\section{Conflicts of Interest}

The authors have no financial conflicts of interest.

\section{Ethical Statement}

Animal care and operating procedures were approved by the Hallym University Institutional Animal Care and Use Committee, Chuncheon, Korea (Hallym2013-20).

\section{REFERENCES}

1. Lee JH, Lee SJ, Kim SJ, Kim KH, Kim YL, Song JE, et al. Effect of silk in Silk/PLGA hybrid films on attachment and proliferation of human aortic endothelial cells. Polymer Korea 2013;37:127-134.

2. Mondal M, Trivedy K, Kumar SN. The silk proteins, sericin and fibroin in silkworm, Bombyx mori Linn.,-a review. Caspian J Env Sci 2007;5:63-76.

3. Shimura K, Kikuchi A, Ohtomo K, Katagata Y, Hyodo A. Studies on silk fibroin of Bombyx mori. I. Fractionation of fibroin prepared from the posterior silk gland. J Biochem 1976;80:693-702.

4. Yilgor P, Sousa RA, Reis RL, Hasirci N, Hasirci V. 3D Plotted PCL scaffolds for stem cell based bone tissue engineering. Macromol Symp 2008; 269:92-99.

5. Liu TL, Miao JC, Sheng WH, Xie YF, Huang Q, Shan YB, et al. Cytocompatibility of regenerated silk fibroin film: a medical biomaterial applicable to wound healing. J Zhejiang Univ Sci B 2010;11:10-16.
6. Choi YH, Kim MG, Ahn DH, Hong SH, Lee JY, Kim HS, et al. The wound healing effect of a silk fibroin film on cutaneous burn of hairless mice. J Korean Surg Soc 2010;79:421-427.

7. Barnett SE, Varley SJ. The effects of calcium alginate on wound healing. Ann R Coll Surg Engl 1987;69:153-155.

8. Wang L, Wang Y, Qu J, Hu Y, You R, Li M. The cytocompatibility of genipin-crosslinked silk fibroin films. J Biomat Nanobiotech 2013;4:213-221.

9. Schneider A, Wang XY, Kaplan DL, Garlick JA, Egles C. Biofunctionalized electrospun silk mats as a topical bioactive dressing for accelerated wound healing. Acta Biomat 2009;5:2570-2578.

10. Min BM, Lee G, Kim SH, Nam YS, Lee TS, Park WH. Electrospinning of silk fibroin nanofibers and its effect on the adhesion and spreading of normal human keratinocytes and fibroblasts in vitro. Biomaterials 2004; 25:1289-1297.

11. Abramo F, Argiolas S, Pisani G, Vannozzi I, Miragliotta V. Effect of a hydrocolloid dressing on first intention healing surgical wounds in the dog: a pilot study. Aust Vet J 2008;86:95-99.

12. Lim HJ, Kim HT, Oh EJ, Choi JH, Ghim HD, Pyun DG, et al. Effect of newly developed pectin/CMC dressing materials on three different types of wound model. Polymer Korea 2010;34:363-368.

13. Chakravarthy D, Rodway N, Schmidt S, Smith D, Evancho M, Sims R. Evaluation of three new hydrocolloid dressings: retention of dressing integrity and biodegradability of absorbent components attenuate inflammation. J Biomed Mater Res 1994;28:1165-1173.

14. Brown-Etris M, Milne C, Orsted H, Gates JL, Netsch D, Punchello M, et al. A prospective, randomized, multisite clinical evaluation of a transparent absorbent acrylic dressing and a hydrocolloid dressing in the management of Stage II and shallow Stage III pressure ulcers. Adv Skin Wound Care 2008;21:169-174.

15. Chen YH, Dong WR, Chen QY, Zhao BL, Zou ZZ, Xiao YQ, et al. [Biological dressing with human hair keratin-collagen sponge-poly 2-hydroxyethyl methacrylate composite promotes burn wound healing in SD rats]. Nan Fang Yi Ke Da Xue Xue Bao 2007;27:1621-1626.

16. Silver GM, Robertson SW, Halerz MM, Conrad P, Supple KG, Gamelli RL. A silver-coated antimicrobial barrier dressing used postoperatively on meshed autografts: a dressing comparison study. J Burn Care Res 2007;28:715-719.

17. Holland AJ, Ward D, Farrell B. The influence of burn wound dressings on laser Doppler imaging assessment of a standardized cutaneous injury model. J Burn Care Res 2007;28:871-878.

18. Singh R, Kumar D, Kumar P, Chacharkar MP. Development and evaluation of silver-impregnated amniotic membrane as an antimicrobial burn dressing. J Burn Care Res 2008;29:64-72.

19. Sezer AD, Hatipoğlu F, Cevher E, Oğurtan Z, Baş AL, Akbuğa J. Chitosan film containing fucoidan as a wound dressing for dermal burn healing: preparation and in vitro/in vivo evaluation. AAPS PharmSciTech 2007; 8:Article 39.

20. Dell H. Biomaterials: silk spin-off. Nature 2006;441:821.

21. Minoura N, Aiba S, Higuchi M, Gotoh Y, Tsukada M, Imai Y. Attachment and growth of fibroblast cells on silk fibroin. Biochem Biophys Res Commun 1995;208:511-516.

22. Santin M, Motta A, Freddi G, Cannas M. In vitro evaluation of the inflammatory potential of the silk fibroin. J Biomed Mater Res 1999;46:382389.

23. Sugihara A, Sugiura K, Morita H, Ninagawa T, Tubouchi K, Tobe R, et al. Promotive effects of a silk film on epidermal recovery from fullthickness skin wounds. Proc Soc Exp Biol Med 2000;225:58-64. 